\title{
Treatment of relapsing Clostridium difficile infection using fecal microbiota transplantation
}

This article was published in the following Dove Press journal:

Clinical and Experimental Gastroenterology

27 December 2013

Number of times this article has been viewed

\section{Rahul Pathak' \\ Hill Ambrose Enuh' \\ Anish Patel' \\ Prasanna Wickremesinghe ${ }^{2}$ \\ 'Department of Internal Medicine, New York Medical College, Internal Medicine Program at Richmond University Medical Center, Staten Island, NY, USA; ${ }^{2}$ Department of Gastrointestinal Medicine, New York Medical College, Internal Medicine Program at Richmond University Medical Center, Staten Island, NY, USA}

Correspondence: Prasanna Wickremesinghe New York Medical College, Internal Medicine Program at Richmond University Medical Center, Department of Gastrointestinal Medicine, 355 Bard Avenue, Staten Island, NY, USA, 10310 $\mathrm{Tel}+17188182419$ Email pcwickpc@aol.com
Background: Clostridium difficile infection (CDI) has become a global concern over the last decade. In the United States, CDI escalated in incidence from 1996 to 2005 from 31 to $64 / 100,000$. In 2010 , there were 500,000 cases of CDI with an estimated mortality up to 20,000 cases a year. The significance of this problem is evident from the hospital costs of over 3 billion dollars annually. Fecal microbiota transplant (FMT) was first described in 1958 and since then about 500 cases have been published in literature in various small series and case reports. This procedure has been reported mainly from centers outside of the United States and acceptance of the practice has been difficult. Recently the US Food and Drug Administration (FDA) labeled FMT as a biological drug; as a result, guidelines will soon be required to help establish it as a mainstream treatment. More US experience needs to be reported to popularize this procedure here and form guidelines.

Method: We did a retrospective review of our series of patients with relapsing CDI who were treated with FMT over a 3-year period. We present our experience with FMT at a community hospital as a retrospective review and describe our procedure.

Results: There were a total of 12 patients who underwent FMT for relapsing $C$. difficile. Only one patient failed to respond and required a second FMT. There were no complications associated with the transplant and all patients had resolution of symptoms within 48 hours of FMT.

Conclusion: FMT is a cheap, easily available, effective therapy for recurrent CDI; it can be safely performed in a community hospital setting with similar results.

Keywords: fecal microbiota transplantation, Clostridium difficile infection

\section{Introduction}

An estimated 3 million cases of Clostridium difficile infection (CDI) occur every year and increase hospital costs by US\$3.2 billion. ${ }^{1,2}$ Hospital stays in excess of 7 days increase the risk of contracting CDI five-fold. ${ }^{3,4}$ Older ( $>65$ years) patients, ${ }^{5}$ immunocompromised patients, ${ }^{6}$ peripartum patients, those with inflammatory bowel disease (IBD), ${ }^{7}$ and severe comorbidities ${ }^{8}$ are at an increased risk. Cases of extracolonic involvements with reactive arthritis have been reported. ${ }^{9}$ Current management for mild CDI includes oral metronidazole. Persistent or moderately severe CDI, especially in hospitalized patients over 65 years of age, needs to be treated with oral vancomycin. The US Food and Drug Administration (FDA) has approved fidaxomicin, which is as effective as vancomycin and is associated with fewer recurrences to treat CDI. ${ }^{10} \mathrm{Up}$ to $20 \%$ of patients relapse after an initial first treatment. ${ }^{11-13}$ Patients who experience one recurrence have a $40 \%$ risk of another recurrence, and those with two or more episodes face a $60 \%$ risk. ${ }^{11,14,15}$ Fecal microbiota transplant (FMT) is gaining acceptance in the 
United States as an effective treatment for recurrent CDI. Recent review articles of FMT for recurrent CDI have been published which found a primary cure rate of $91 \%$ (defined as the resolution of symptoms without recurrence within 90 days of FMT), and a secondary cure rate of $98 \%$ (defined as the resolution of symptoms after one further course of vancomycin with or without repeat FMT). ${ }^{16-18}$ These cure rates include patients with recurrent or refractory CDI. ${ }^{16,19-22}$ The low cost, safety, efficacy, and ease of FMT make it an attractive option for these difficult cases. ${ }^{18,20,23,24}$

Recently, the FDA has determined that FMT is a biological drug and needs to be regulated; part of that regulation is that clinicians using FMT as a treatment need to submit a treatment protocol and an institutional review board (IRB) approval from their center to obtain an Investigational New Drug (IND) number from the FDA. ${ }^{25}$ An IND sponsor has to conduct their work in accordance with the protocol described in the IND, must report any deviations, and must file reports, among other requirements. This is an intensive process, but thankfully, for now the FDA has decided to use their executive discretion and not enforce the IND process. It remains to be seen how long this will continue before an increased regulatory oversight of one kind or another is going to be the norm.

More US experience needs to be reported to reintroduce this procedure in the US and form guidelines. We describe our experience with FMT over the last 3 years.

\section{Methods}

\section{Patient selection}

Patient selection was determined by severity of CDI. In fulminant cases, we used FMT as a first treatment to prevent further clinical deterioration. We selected patients who met the following criteria and/or presented as follows:

1. Mild CDI in young patients not admitted to the hospital was treated with oral metronidazole. These patients were not candidates for FMT in our study.

2. Patients with recurrent or relapsing CDI; ${ }^{26}$ this included patients with at least three episodes of mild to moderate CDI and a failure of initial treatment with vancomycin with or without an additional antibiotic such as fidaxomicin. ${ }^{26}$ Vancomycin was given at a therapeutic dose for 2 weeks followed by pulse therapy for 4 weeks. Pulse therapy allows for the spores to germinate in the absence of antibiotics since vancomycin does not act on the spore form. Once the spores have converted to the fully functional vegetative, toxin-producing forms, they are susceptible to the pulse antibiotic. It was started at $125 \mathrm{mg}$ PO (taken orally), q6 hrs (every six hours), for
2 weeks and then $125 \mathrm{mg}$ q6 hrs, every third day for 4 weeks. A higher dose of $250 \mathrm{mg}$ was given for recurrences in the same schedule. Patients who failed treatment with this regimen were considered for FMT.

3. Patients with at least two episodes of severe CDI resulting in hospitalization and associated with significant morbidity ${ }^{26}$ were considered for FMT.

4. Patients with moderate CDI not responding to standard therapy (vancomycin) for at least 1 week $^{26}$ were considered for FMT.

5. Patients with severe and/or fulminant $C$. difficile colitis with no response to standard therapy for 48 hours, ${ }^{26}$ or if toxic megacolon developed, were considered for FMT.

\section{Patient exclusion}

Those patients whose gastrointestinal (GI) tract could not be used were not considered for FMT. These included conditions like gastrointestinal malignancy, obstruction, or perforations.

\section{Donor selection}

We preferred family members or first-degree relatives. When related donors were not available, healthy volunteers were selected. Family members who live with a recipient have the advantage of being exposed to the same risk factors and thereby minimize the risk of transmitting an unexposed infectious agent. ${ }^{26}$ However, they may also be at a higher risk of being a $C$. difficile carrier because of prolonged exposure, and therefore need to be tested prior to donating a sample.

\section{Donor exclusion criteria}

Donors were screened carefully and required testing for potential infectious agents that may be transmitted via FMT to the recipient. Donors with conditions such as human immunodeficiency virus (HIV), sexually transmitted diseases (STDs), and Hepatitis B and C were excluded. If donor testing was unavailable due to financial or time constraints, we would suspend some or all donor testing as long as a detailed donor history was available for risk factors and proper documentation; consent was obtained to do so. Patients and donors signed a culpability waiver if they refused testing prior to the procedure, absolving the physician and the institution of any pursuant responsibility.

\section{Donor screening questionnaire}

We used a list of questions to screen donors prior to accepting samples from them. The following were used as exclusion 
criteria for donors: 1) known exposure for HIV, Hepatitis, or STDs; 2) high-risk sexual behaviors; 3) drug use, tattoos or body piercing, imprisonment, or other high-risk behavior; 4) known current communicable disease; 5) GI comorbidities such as IBD or GI malignancy; and 6) antibiotic use within the preceding 90 days.

\section{Donor blood testing}

Donor blood testing consisted of testing for the following: 1) HIV types 1and 2; 2) Hepatitis A, B, and C; and 3) STDs.

\section{Donor stool testing}

Donor stool testing consisted of testing for the following: 1) bacterial culture for enteric pathogens; 2) ova and parasites; and 3) C. difficile toxins $\mathrm{A}$ and $\mathrm{B}$.

\section{Procedure Donor}

The donation procedure was completed as soon as the screening procedure was finished. To facilitate the collection of stool samples with a liquid consistency, the donor was given a $10 \mathrm{mg}$ dose of magnesium citrate the night prior to stool collection.

\section{Patient}

Patients stopped oral vancomycin or fidaxomicin use 24 hours prior to the procedure. The night before, the patient was given a standard polyethylene glycol colonoscopy bowel preparation. This was done to reduce the bacterial load in the colon by mechanical cleansing and to facilitate colonoscopy to introduce the donor stool sample.

\section{Fecal solution preparation}

The stool sample was fresh and was collected within 6 hours of the procedure. Universal precautions (gown, gloves, eye protection) were used during stool processing. About six to eight tablespoons of donor stool was added to $1 \mathrm{~L}$ of tap water and shaken vigorously to prepare the effluent for transplant.

\section{Procedure}

The procedure was explained, the risks and options discussed, and informed consent was obtained. We performed our FMT via colonoscopy. We used a modified endoscopic retrograde cholangiopancreatography (ERCP) catheter to deliver the fecal suspension. The colonoscope was advanced to the cecum, or preferably to the terminal ileum, when possible. We instilled about 400-500 cc of the suspension in the terminal ileum and cecum, then 50-60 cc aliquots every $10 \mathrm{cms}$ when withdrawing the colonoscope. The patients were given 2 tablets of diphenoxylate/atropine to slow the excretion of the transplanted effluent. Antibiotics and proton pump inhibitors were not resumed. Eleven of our procedures were done through colonoscopy; we performed one other procedure using an infusion in the nasoduodenal tube. Biopsies were taken when thought necessary.

\section{Outcomes and follow-up measures}

Diarrhea usually resolved within 48 hours after the procedure. A successful treatment was determined by the resolution of diarrhea, a fall in white cell count, or absence of fever and an improvement in vital signs. A week later, a 2-month course of the probiotic Saccharomyces boulardii (250 mg PO, twice daily) was started, and the patient was instructed to report any signs of CDI after the procedure was done. If diarrhea or fever occurred, the patient was asked to return and their stool was tested for $C$. difficile. Patients were followed-up with either in clinic visits, or nursing home visits.

\section{Results}

We treated a total of 12 patients with FMT over the last 3 years. Table 1 shows the details of their presentation. Our patients ranged in age from 37 to 92 years. Follow-up on our patients ranged from 2-30 months. All our patients had recurrent disease and were not responding to the standard therapy for CDI. Patients' symptoms resolved within 48 hours of receiving FMT, in all but one patient. This patient was initially treated for a perforated appendix with antibiotics and developed CDI from the long-term treatment. She was then treated for CDI, but failed to respond to treatment during 6 months of antibiotic therapy. She became septic, went into shock, and was admitted to the intensive care unit (ICU) for further management. FMT was done as an emergency treatment by one of the physicians at our hospital. The donor was the husband who had been tending after this patient, in close contact, for the 6 months prior to the FMT. He refused to be stool tested prior to the procedure in order to allow the procedure to be done as soon as possible. The patient failed to respond to this treatment and required a repeat FMT. The second time around a healthy volunteer donor was selected because we believed the husband was a carrier. This could explain the lack of response from the first treatment. The patient responded to the second FMT and improved enough to be sent back to a nursing home for care. The second FMT was done by nasoduodenal route using a nasoduodenal tube. Unfortunately, at the nursing home this patient developed a urinary tract infection (UTI) after a few months and was treated 
Table I Summary of FMT among 12 patients over a 3 year period in a community hospital

\begin{tabular}{|c|c|c|c|c|c|c|c|c|c|}
\hline $\mathbf{S N}$ & $\begin{array}{l}\text { Age } \\
\text { (years) }\end{array}$ & Sex & Donor & Inciting event & $\begin{array}{l}\text { Length } \\
\text { of disease }\end{array}$ & $\begin{array}{l}\text { Prior } \\
\text { treatment }\end{array}$ & $\begin{array}{l}\text { Colonoscopy } \\
\text { finding }\end{array}$ & $\begin{array}{l}\text { Follow-up } \\
\text { in months }\end{array}$ & Note \\
\hline 1 & 90 & $\mathrm{~F}$ & Daughter & Age, Abx for UTI & $\begin{array}{l}\text { Recurrent } \\
>\text { I year }\end{array}$ & Vanc/fidaxo & $\begin{array}{l}\text { Colitis, melanosis } \\
\text { coli }\end{array}$ & 8 & $\begin{array}{l}\text { No recurrence } \\
\text { after FMT }\end{array}$ \\
\hline 2 & 85 & $M$ & Son & Abx, VDRF & $\begin{array}{l}>10 \text { episodes, } \\
>1 \text { year }\end{array}$ & Vanc/fidaxo & $\begin{array}{l}\text { Colitis, } \\
\text { diverticulosis, } \\
\text { hemorrhoid }\end{array}$ & 20 & Had FMT in the past \\
\hline 3 & 65 & $\mathrm{~F}$ & Son & UTI, Abx & $>10$ episodes & Vanc & $\begin{array}{l}\text { Pseudomembranous } \\
\text { colitis }\end{array}$ & 26 & \\
\hline 4 & 84 & $\mathrm{~F}$ & Son & VDRF, HCAP, Abx & $\begin{array}{l}\text { Multiple } \\
\text { episodes } \\
\text { in } 2 \text { years }\end{array}$ & Vanc/metro & $\begin{array}{l}\text { Colitis, } \\
\text { internal hemorrhoid }\end{array}$ & 29 & \\
\hline 5 & 75 & $\mathrm{~F}$ & Daughter & $\begin{array}{l}\text { Abx, ruptured } \\
\text { appendix }\end{array}$ & $>6$ months & $\begin{array}{l}\text { Vanc/metro/ } \\
\text { fidaxo }\end{array}$ & Colitis & 4 & $\begin{array}{l}\text { Developed UTI and } \\
\text { got CDI from Abx, } \\
\text { refused treatment } \\
\text { and expired }\end{array}$ \\
\hline 6 & 85 & $\mathrm{~F}$ & Daughter & $\begin{array}{l}\text { Adenocarcinoma } \\
\text { left colon and } \\
\text { diverticulitis }\end{array}$ & $>6$ months & Vanc & Colitis, diverticulitis & 19 & \\
\hline 7 & 72 & $M$ & Sister & $\begin{array}{l}\text { Immunosuppressed/ } \\
\text { renal transplant }\end{array}$ & 6 months & $\begin{array}{l}\text { Vanc/metro/ } \\
\text { fidaxo }\end{array}$ & Colitis & 6 & \\
\hline 8 & 68 & $\mathrm{~F}$ & Husband & PNA and antibiotics & 4 months & Vanc & Colitis & 26 & Had FMT in the past \\
\hline 9 & 72 & $M$ & Son & Cancer/Abx, PNA & $>4$ episodes & $\begin{array}{l}\text { Vanc/metro/ } \\
\text { fidaxo }\end{array}$ & Diverticulosis & 10 & \\
\hline 10 & 51 & $\mathrm{~F}$ & Daughter & UTI, septicemia & $>6$ months & Vanc, fidaxo & C. Difficile & 8 & \\
\hline II & 37 & $\mathrm{~F}$ & Niece & Antibiotics, UTI & $\begin{array}{l}3 \text { episodes } \\
\text { in I year }\end{array}$ & Vanc, fidaxo & Colitis & 4 & \\
\hline 12 & 79 & $M$ & Wife & $\begin{array}{l}\text { Ulcerative colitis, } \\
\text { Abx }\end{array}$ & $>6$ months & Vanc/fidaxo & Hemorrhoid, UC & 2 & \\
\hline
\end{tabular}

Abbreviations: FMT, fecal microbiota transplant; SN, serial number; F, female; M, male; Abx, antibiotics; UTI, urinary tract infection; Vanc, vancomycin; fidaxo, fidaxomycin; VDRF, ventilator dependent respiratory failure; HCAP, health care associated pneumonia; metro, metronidazole; PNA, pneumonia; int, internal; CDI, Clostridium difficile; UC, ulcerative colitis.

with antibiotics, which in turn led to her developing CDI again. She became septic once again, and was admitted to the ICU on a ventilator, and expired after refusing further treatments. Two of our patients had stool transplants done many years ago and chose to have repeat FMT when they developed resistant CDI again. However, none of our patients developed recurrences within 90 days of the transplant. We had two patients who received FMT while in the ICU. The others responded with improved vital signs and resolution of symptoms.

There were no complications with transplants in any of our patients. They did not develop any infections from FMT and their symptoms resolved within 48 hours. Their elevated white cell counts returned to normal and their vital signs improved. The primary and secondary cure rates in our study were $91.66 \%$ and $100 \%$, respectively. Our cure rates are similar to other published series, even though ours is a community hospital setting.

\section{Discussion}

Acceptance of FMT has been difficult. Unlike other donors, FMT donors do lose miss anything. The notion of donating stool is not as noble as donating a kidney or part of your liver. The outcomes however, are incomparably good. The success rates of FMT have been shown to be better than currently available treatment. The overall perception and acceptance of FMT improved when the transplant and its success rate were explained to family members.

FMT is easy to perform and cost efficient. It does not require intensive care or monitoring and can be done at a community hospital setting quite effectively, as seen in our study.

We gave patients $S$. boulardii (Florastor) for 2 months after the procedure. S. boulardii was shown to be of modest benefit in patients treated with high doses of vancomycin. It may be argued that there was some benefit from Florastor and not just the FMT in these results. We realize that this is a concern. However, our patients received the probiotic for weeks prior to the transplant as well, while taking oral antibiotic treatment for CDI. The probiotic failed to treat the infection prior to the transplant. Florastor was restarted a week after the transplant when symptoms had resolved. Symptoms resolved within 24-48 hours of the transplant and the probiotics were 
started only 1 week after the procedure. The beneficial effects of probiotics with FMT remain to be studied.

The incidence of CDI continues to increase with more patients developing refractory or recurrent infection. The costs of treating these infections place a huge burden on our resources in terms of morbidity, mortality, and cost. Vancomycin capsules cost an average of US $\$ 1,800$ for a 14-day treatment at $125 \mathrm{mg}$ QID (four times daily). Even with insurance the copayment is very high. A treatment with $250 \mathrm{mg}$ PO, QID runs to approximately US\$2,200 per patient, and these costs do not include 4 weeks of pulse therapy. A course of fidaxomicin for CDI costs approximately US\$3,500. Now available, generic intravenous vancomycin vials contain an injectable liquid form that can effectively be taken orally. The cost of the entire treatment by this route runs to approximately US\$40. Patients who cannot afford the treatment or do not have insurance can affordably be treated this way. FMT is a simple procedure, universally available, low cost, highly effective treatment for recurrent CDI. The cost of FMT from a donor who is a family member, or a healthy volunteer and already tested for transmissible diseases, is currently negligible compared to the alternatives. We have the opportunity with our publications to shape the regulatory process before they are established to keep the costs low. More descriptive papers are needed to help establish this procedure as a mainstream treatment, even to the point where it could be the first treatment offered.

The practice of FMT, however, is still not common or routine among gastroenterologists in the US. Recently, the FDA determined that FMT is a biological drug and needs to be regulated..$^{25}$ Part of that regulation is that clinicians using FMT as a treatment need to submit a treatment protocol, and an IRB approval from their institute to obtain an IND number from the FDA. A sponsor of an IND has to conduct their work in accordance with the protocol described in the IND, report any deviations, and file reports, among other duties. This is an intensive process, but thankfully, for now the FDA has decided to use their executive discretion and not enforce the IND process. It remains to be seen how long this will continue before an increased regulatory oversight of one kind or another is going to be imposed. The indications and best methods of administration are being published in more papers in recent years and may help to evolve guidelines and procedures for FMT. Further research is important to establish different effective methods to administer FMT. More recently, FMT via ingestion of fecal microbes contained in double over-encapsulated gelatin capsules has been described in an abstract presented at the ID Week conference in San Francisco in 2013; this delivery method appears to be a convenient and effective approach to arrest the cycle of recurrent $\mathrm{CDI}{ }^{27}$

FMT may be done by nasogastric and nasoduodenal tubes, as retention enemas, or via colonoscopy. Colonoscopy provides the benefit of delivering the bacteria at the affected site, as well as examining for any coexistent pathology. However, it also runs the risk of perforation in cases of severe toxic megacolon caused by CDI. There is a potential risk of transmission of infectious agents contained in the stool, but this may be abridged by using healthy donors with good bowel function and testing for common pathogens (bacteria, viral, and parasite) in both blood and stool.

Studies have been recommended to decipher the role of intestinal microbiota in chronic diseases such as IBDs (Crohn's disease and ulcerative colitis), ${ }^{28}$ metabolic syndrome cancer, obesity, ${ }^{29}$ diabetes, autism, myasthenia gravis, rheumatoid arthritis, parkinsonism, chronic fatigue syndrome and other conditions, ${ }^{24,27}$ and in future, more indications for FMT may be proposed.

FMT has evidence-based benefits. It has moved from being an unappealing procedure to the point where physicians have begun talking about its high cure rates in more recent studies. The reemergence of this therapy in the last few years can be attributed to the high costs of treating CDI, the increasing incidence of recurrent disease, and the morbidity it causes to patients in the hospital.

\section{Conclusion}

FMT is an effective method for the treatment of recurrent and relapsing CDI. It is cost effective and can be performed at a community hospital, as well as any university hospital setting with equivalent results.

\section{Disclosure}

The authors reports no conflicts of interest in this work.

\section{References}

1. McFarland LV, Mulligan ME, Kwok RY, Stamm WE. Nosocomial acquisition of Clostridium difficile infection. N Engl J Med. 1989;320: 204-210.

2. O'Brien JA, Lahue BJ, Caro JJ, Davidson DM. The emerging infectious challenge of clostridium difficile-associated disease in Massachusetts hospitals: clinical and economic consequences. Infect Control Hosp Epidemiol. 2007;28:1219-1227.

3. Ananthakrishnan AN, McGinley EL, Saeian K, Binion DG. Temporal trends in disease outcomes related to Clostridium difficile infection in patients with inflammatory bowel disease. Inflamm Bowel Dis. 2011;17: 976-983.

4. Pepin J, Saheb N, Coulombe MA, et al. Emergence of fluoroquinolones as the predominant risk factor for Clostridium difficile-associated diarrhea: a cohort study during an epidemic in Quebec. Clin Infect Dis. 2005;41 $1254-1260$ 
5. Pepin J, Alary ME, Valiquette L, et al. Increasing risk of relapse after treatment of Clostridium difficile colitis in Quebec, Canada. Clin Infect Dis. 2005;40:1591-1597.

6. Hookman P, Barkin JS. Clostridium difficile associated infection, diarrhea and colitis. World J Gastroenterol. 2009;15:1554-1580.

7. Ananthakrishnan AN, Issa M, Binion DG. Clostridium difficile and inflammatory bowel disease. Gastroenterol Clin North Am. 2009;38: 711-728.

8. Aslam S, Hamill RJ, Musher DM. Treatment of Clostridium difficileassociated disease: old therapies and new strategies. Lancet Infect Dis. 2005;5:549-557.

9. Enuh H, Saverimuttu J, Nfonoyim J, Bloomfield D, Habtegebriel Y. Reactive Arthritis from Non-Antibiotic Related Clostridia Difficile Diarrhea. The Internet Journal of Rheumatology. 2013:8.

10. Louie TJ, Miller MA, Mullane KM, et al. Fidaxomicin versus vancomycin for Clostridium difficile infection. NEngl J Med. 2011;364: $422-431$.

11. Kelly CR, de Leon L, Jasutkar N. Fecal microbiota transplantation for relapsing Clostridium difficile infection in 26 patients: methodology and results. J Clin Gastroenterol. 2012;46:145-149.

12. McFarland LV, Elmer GW, Surawicz CM. Breaking the cycle: treatment strategies for 163 cases of recurrent Clostridium difficile disease. Am J Gastroenterol. 2002;97:1769-1775.

13. McFarland LV, Surawicz CM, Rubin M, Fekety R, Elmer GW, Greenberg RN. Recurrent Clostridium difficile disease: epidemiology and clinical characteristics. Infect Control Hosp Epidemiol. 1999;20: 43-50.

14. Kelly CP. A 76-year-old man with recurrent Clostridium difficileassociated diarrhea: review of C. difficile infection. JAMA. 2009;301: 954-962.

15. McFarland LV. Alternative treatments for Clostridium difficile disease: what really works? J Med Microbiol. 2005;54:101-111.

16. Brandt LJ, Aroniadis OC, Mellow M, et al. Long-term follow-up of colonoscopic fecal microbiota transplant for recurrent Clostridium difficile infection. Am J Gastroenterol. 2012;107:1079-1087.

17. Musgrave CR, Bookstaver PB, Sutton SS, Miller AD. Use of alternative or adjuvant pharmacologic treatment strategies in the prevention and treatment of Clostridium difficile infection. Int J Infect Dis. 2011;15: e438-e448.
18. Rohlke F, Stollman N. Fecal microbiota transplantation in relapsing Clostridium difficile infection. Therap Adv Gastroenterol. 2012;5: 403-420.

19. Garborg K, Waagsbo B, Stallemo A, Matre J, Sundoy A. Results of faecal donor instillation therapy for recurrent Clostridium difficileassociated diarrhoea. Scand J Infect Dis. 2010;42:857-861.

20. Rohlke F, Surawicz CM, Stollman N. Fecal flora reconstitution for recurrent Clostridium difficile infection: results and methodology. J Clin Gastroenterol. 2010;44:567-570.

21. Yoon SS, Brandt LJ. Treatment of refractory/recurrent C. difficileassociated disease by donated stool transplanted via colonoscopy: a case series of 12 patients. J Clin Gastroenterol. 2010;44:562-566.

22. You DM, Franzos MA, Holman RP. Successful treatment of fulminant Clostridium difficile infection with fecal bacteriotherapy. Ann Intern Med. 2008;148:632-633.

23. Ho N, Prasad V. Clostridium difficile diarrhea and fecal transplantation. J Clin Gastroenterol. 2011;45:742-743.

24. van Nood E, Speelman P, Kuijper EJ, Keller JJ. Struggling with recurrent Clostridium difficile infections: is donor faeces the solution? Euro Surveill. 2009:14.

25. Department of Health and Human Services. US Food and Drug Administration letter. Available from http://highroadsolution.com/ file_upload_2/files/fda=response=letter=to=fmt=inquiry.pdf. Accessed December 4, 2013.

26. Bakken JS, Borody T, Brandt LJ, et al. Treating Clostridium difficile infection with fecal microbiota transplantation. Clin Gastroenterol Hepatol. 2011;9:1044-1049.

27. Louie TJ, Miller MA, Crook DW, et al. Effect of age on treatment outcomes in Clostridium difficile infection. JAm Geriatr Soc. 2013;61: 222-230.

28. Brandt LJ. American Journal of Gastroenterology Lecture: Intestinal microbiota and the role of fecal microbiota transplant (FMT) in treatment of C. difficile infection. Am J Gastroenterol. 2013;108: 177-185.

29. Festi D, Schiumerini R, Birtolo C, et al. Gut microbiota and its pathophysiology in disease paradigms. Dig Dis. 2011;29:518-524.
Clinical and Experimental Gastroenterology

\section{Publish your work in this journal}

Clinical and Experimental Gastroenterology is an international, peerreviewed, open access journal, publishing all aspects of gastroenterology in the clinic and laboratory, including: Pathology, pathophysiology of gastrointestinal disease; Investigation and treatment of gastointestinal disease; Pharmacology of drugs used in the alimentary tract;

\section{Dovepress}

Immunology/genetics/genomics related to gastrointestinal disease. This journal is indexed on CAS. The manuscript management system is completely online and includes a very quick and fair peer-review system. Visit http://www.dovepress.com/testimonials.php to read real quotes from published authors. 